Alexander Dubjansky ${ }^{1}$, Mykola Bodnar ${ }^{2}$

1. Department of Automotive Engineering, Lviv Polytechnic National University, Ukraine, Lviv, S. Bandery Street 12, E-mail: adub@i.ua

2. Department of Automotive Engineering, Lviv Polytechnic National University, Ukraine, Lviv, S. Bandery Street 12, E-mail: bodnarmykola@gmail.com

\title{
INFLUENCE OF CONSTRUCTIVE AND OSCILLATORY PARAMETERS OF BUSES SUSPENSION ON THE ROAD SAFETY
}

Received: April 11, 2018 / Revised: September 28, 2018 / Accepted: December 26, 2018

(C) Dubjansky A., Bodnar M., 2018

Abstract. Oscillatory processes in bus suspension that occur during movement, affect not only on smoothness of motion but also on road safety, especially in relation to the front steering wheels. Based on the computer program AVTO4 which allows us to evaluate the smoothness of the car, we developed a new methods, with the help of which it is possible to calculate the number of detachments of the front controlled wheels of the bus from the road surface, and, in accordance with the results obtained, to select the optimum oscillatory suspension parameters for these driving conditions. In addition, this method also makes it possible to evaluate how the wheel rolls on the road surface varies depending on its vertical oscillations when the bus parameters (the degree of loading) change, as well as the parameters of its unsprung suspension masses (tire damping coefficient, unsprung weight, stiffness tires). Studies were carried out by simulating the movement of a bus along a cobblestone road as the speed of its movement changes. The results obtained are presented in the form of tables and graphs.

The results of the research showed that the optimal oscillating parameters of the suspension of the front controlled wheels of the bus, which satisfy the conditions of smoothness motion, do not always positively affect the number of wheel detachments from the road, and hence the road safety. Therefore, when we choose these parameters, it is necessary to take into account this discrepancy.

The presented method makes it possible to select these parameters at the design stage of any types of vehicles, as well as to change the type of pavement, that is, there is no need to conduct fullscale tests, which saves time and money when creating new vehicle designs.

Keywords: constructive parameters, oscillatory parameters, air suspension, controlled wheels, wheel detachment, unsprung weight, cobblestones, road safety, smoothness of motion.

\section{Theoretical Part}

Choosing the right parameters of such suspension components like springs, pneumatic cylinders, shock absorbers for buses, operated in various road conditions, is very important for ensuring optimal smoothness of moving, as well as the possibility of rolling wheels without detachment from the road.

The difficulty of selection these parameters explains by the fact that forces, which are transmitted to the bus body, depends not only on the bus constructive parameters: its mass and its distribution (moments of inertia) in the longitudinal and transverse planes, the rigidity of the pneumatic cylinders, springs and tires, the number of axes and their location relative to the centre of gravity. These forces also depend on other factors: micro and macro profile of the road, degree of the bus load, speed, uniformity of fuel supply etc. Speed of the bus, when occur continuous vertical oscillations of wheels, accompanied by detachment from the road surface, is one of the most objective measures of speed properties and safety conditions.

Proceeding from this premise, due to the fact, that when wheels are tearing off the road surface and the two-way communication is broken, a great number of experiments held for establishing the impact of a number of constructive parameters of pneumatic suspension on the vertical oscillations of the wheels [6]. 


\section{Influence of Constructive and Oscillatory Parameters of Buses Suspension on the Road Safety}

During research was used the spectral theory of cushioning developed by Silaev A.A. [6]. In particular the energy spectrum of the road reactions can be obtained by an expression:

$$
S_{p}(\omega)=\left\{c-m \omega^{2}+i \omega \mu-(c+i \omega \mu) \cdot\left[W_{z}(i \omega)+W_{\theta}(i \omega)\right] \cdot l\right\}^{2} \Phi(\omega),
$$

where $W_{z}(i \omega)$ is the amplitude-frequency characteristic of the body vertical oscillations; $W_{\theta}(i \omega)$ is the amplitude-frequency characteristic of the lengthwise-angular vibrations; $\Phi(\omega)$ is the energy amplitude spectrum; $\mu$ is the shock absorber resistance coefficient; $m$ is the mass of the wheel; $l$ is the distance from the centre of weight to the axis of the wheel; $\omega$ is the frequency; $c$ is the stiffness of the elastic element.

After determining the quadratic value of the wheel's reaction and the speed of its changing by the formulas:

$$
\sigma_{r}^{2}=1 / \pi \int_{0}^{\infty} S_{p}(\omega) d \omega, \sigma_{\dot{r}}^{2}=1 / \pi \int_{0}^{\infty} S_{\dot{p}}(\omega) d \omega,
$$

from which the number of wheel tearing off the road surface could be obtained.

Wheel detachment from the road surface associated with the dynamic reaction of road surface and occurs only when the reaction of the road surface (2) on the wheel is equal to zero. The number detachments per unit of time are equal to half the number of cases when reaction of the road surface is equal zero. For this case, the Rais equation takes a form:

$$
N_{0}=\frac{1}{2 \pi} \cdot \frac{\sigma_{\dot{r}}}{\sigma_{r}} \cdot e^{-\frac{P_{s t}^{2}}{2 \sigma_{r}^{2}}},
$$

where $P_{s t}$ is static deformation of one tire, which can be determine as:

$$
P_{s t}=\frac{G_{i}-G_{u n}}{2},
$$

where $G_{i}$ is the corresponding axle load, $G_{u n}$ - the unsprung mass for the corresponding axle.

Based on the foregoing provisions, it's also possible to define the number of wheel detachments from the road, analysing not only the reaction of the road, but also the deformation of the tire. Wheel detachment from the road surface will occur only when the deformation of the tires will be equal to zero or exceeds its static deformation in the opposite direction. Mathematical expectation of deformation of the tire could be taken as its static deformation, believing that oscillation process equally loads the tire as well as unloads it. Thus, according to equation (4) could be determined the number of detachments per unit of time by substituting dispersion reaction of road surface and the speed of load changes on the wheel by deformation of the tire, the rate of change of this deformation and the static deformation of the tire. Numbers of wheel detachments from the road surface in this case are:

$$
N_{0}=\frac{1}{2 \pi} \cdot \frac{\sigma_{\Delta}}{\sigma_{\dot{\Delta}}} \cdot e^{-\frac{\Delta_{s t}^{2}}{2 \sigma_{\Delta}^{2}}},
$$

where $\sigma_{\Delta}$ is the variance of the tire deformation; $\sigma_{\dot{\Delta}}$ is the speed of changing of the tire deformation dispersion; $\Delta_{s t}$ is the static deformation of the tire.

Computer program AVTO4 [2, 3] allows to take into account most of the options listed above and for a short time, calculate the number of wheel detachments, according to previously described methods [4, 5]. As a model we selected a bus LAZ-4207 with pneumatic suspension being designed for usage on interurban and urban routes. In Tables 1-4 the input constructive parameters of LAZ-4207 and oscillatory parameters of front pneumatic suspension, and tire options, which were specified during the study, are presented. As the variables of constructive parameters of the bus, which were taken into account, were the degree of its loading, and the oscillatory parameters of front suspension - weight of unsprung masses, damping coefficient of tires and their rigidity, which are changed twice from the original value in the 0.25 . 
The basic constructive parameters of the bus LAZ-4207

\begin{tabular}{|l|c|c|}
\hline \multicolumn{1}{|c|}{ Parameter } & Maximum weight & Unloaded weight \\
\hline Vehicle weight, $\mathrm{kg}$ & 13250 & 9440 \\
\hline Weight on the front axle, $\mathrm{kg}$ & 4520 & 2970 \\
\hline Moment of inertia in a longitudinal plane, $\mathrm{kg} \cdot \mathrm{m}^{2}$ & 99560 & 53882 \\
\hline Moment of inertia in the transversal plane, $\mathrm{kg} \cdot \mathrm{m}^{2}$ & 7092 & 4794 \\
\hline The distance from the front axle to the centre of sprung mass, $\mathrm{m}$ & 3.31 \\
\hline The distance from the rear axle to the centre of sprung mass, $\mathrm{m}$ & 1.59 \\
\hline Longitudinal coordinate of the first control point, $\mathrm{m}$ & 3.31 \\
\hline Transverse-coordinate of the first control point, $\mathrm{m}$ & 0.0 \\
\hline Longitudinal coordinate of the second control point, $\mathrm{m}$ & 1.59 \\
\hline Transverse-coordinate of the second control point, $\mathrm{m}$ & 0.0 \\
\hline
\end{tabular}

Table 2

The input data of front suspension of the bus LAZ-4207

\begin{tabular}{|l|c|c|c|}
\hline \multicolumn{1}{|c|}{ Parameter } & $\begin{array}{c}\text { The initial } \\
\text { values }\end{array}$ & $\begin{array}{c}\text { The maximum } \\
\text { value }\end{array}$ & $\begin{array}{c}\text { The minimum } \\
\text { value }\end{array}$ \\
\hline Front axle mass, $\mathrm{kg}$ & 802 & 1002 & 600 \\
\hline Moment of inertia of the front axle in the transversal plane, $\mathrm{kg} \cdot \mathrm{m}^{2}$ & 1000 & 1300 & 750 \\
\hline Spring track of front suspension, $\mathrm{m}$. & \multicolumn{3}{|c|}{1,34} \\
\hline The coefficient of viscous friction in the front suspension, $\mathrm{N} \cdot \mathrm{s} / \mathrm{m}$. & \multicolumn{3}{|c|}{0,01} \\
\hline The maximum force of dry friction in the front suspension, $\mathrm{N}$. & \multicolumn{3}{|c|}{18511} \\
\hline The speed of the maximum force of dry friction, $\mathrm{m} / \mathrm{s}$. & \multicolumn{3}{|c|}{} \\
\hline A shift of zero in the front suspension, $\mathrm{N}$. & \multicolumn{3}{|c|}{} \\
\hline
\end{tabular}

Table 3

The input data of rear suspension of the bus $L A Z-4207$

\begin{tabular}{|c|c|c|c|}
\hline Parameter & $\begin{array}{c}\text { The initial } \\
\text { values }\end{array}$ & $\begin{array}{c}\text { The maximum } \\
\text { value }\end{array}$ & $\begin{array}{c}\text { The minimum } \\
\text { value }\end{array}$ \\
\hline The mass of the rear axle, $\mathrm{kg}$ & 1308 & 1635 & 980 \\
\hline Moment of inertia of the rear axle in the transversal plane, $\mathrm{kg} \cdot \mathrm{m}^{2}$ & 3000 & 3500 & 2750 \\
\hline Spring track of rear suspension, $\mathrm{m}$. & \multicolumn{3}{|c|}{1,6} \\
\hline The coefficient of viscous friction in the rear suspension, $\mathrm{N} \cdot \mathrm{s} / \mathrm{m}$. & \multicolumn{3}{|c|}{24000} \\
\hline The maximum force of dry friction in the rear suspension, $\mathrm{N}$. & \multicolumn{3}{|c|}{2} \\
\hline The speed of the maximum force of dry friction, $\mathrm{m} / \mathrm{s}$. & \multicolumn{3}{|c|}{0,01} \\
\hline A shift of zero in the rear suspension, $\mathrm{N}$. & \multicolumn{3}{|c|}{36130} \\
\hline
\end{tabular}

Table 4

Source data for tires $11 P-22.5$

\begin{tabular}{|l|c|c|c|}
\hline \multicolumn{1}{|c|}{ Parameter } & The initial values & The maximum value & The minimum value \\
\hline The wheel track of the front axis, $\mathrm{m}$. & \multicolumn{3}{|c|}{2,05} \\
\hline The rigidity of the front tyre on one side, $\mathrm{N} / \mathrm{m}$. & 1170000 & 1462500 & 877500 \\
\hline Damping coefficient in front tyre, $\mathrm{N} \cdot \mathrm{s} / \mathrm{m}$. & 13500 & 16875 & 10125 \\
\hline The wheel track of the rear axle, $\mathrm{m}$. & \multicolumn{3}{|c|}{1,82} \\
\hline The rigidity of the rear tyre on one side, $\mathrm{N} / \mathrm{m}$. & 2340000 & 2925000 & 1755000 \\
\hline Damping coefficient in rear tyre, $\mathrm{N} \cdot \mathrm{s} / \mathrm{m}$. & 24000 & 30000 & 18000 \\
\hline
\end{tabular}

The results of calculations

After determining the static deformation of front wheel tire by the formula (5):

- for the unloaded weight $\Delta=\frac{P_{s t}}{c}=\frac{G_{i}-G_{u n}}{2 c}=\frac{(2970-802) 9,8}{2 \cdot 1170000}=0,009 \mathrm{~m}$, 


\section{Influence of Constructive and Oscillatory Parameters of Buses Suspension on the Road Safety}

- for the maximum weight $\Delta=\frac{P_{s t}}{c}=\frac{G_{i}-G_{u n}}{2 c}=\frac{(4520-1308) 9,8}{2 \cdot 1170000}=0,013 \mathrm{~m}$,

we can find the number of tearing off front wheel off the road surface.

Tables 5-9 presents the results of the calculations the number of front suspension wheels for bus LAZ-4207 for two weight conditions with variable parameters of the suspension during the movement on the cobblestone road with different speeds.

Table 5

The results of calculations the numbers of wheels detachments of front suspension for bus LAZ-4207 unloaded weight, when it moves on cobblestone with different speeds

\begin{tabular}{|c|c|c|c|}
\hline $\begin{array}{c}\text { Speed, } \\
\mathrm{km} / \mathrm{h}\end{array}$ & $\begin{array}{c}\text { The variance of the deformation } \\
\text { of the front tire, } \sigma_{\Delta}\end{array}$ & $\begin{array}{c}\text { The variance of speed } \\
\text { deformation of front tire, } \sigma_{\dot{\Delta}}\end{array}$ & $\begin{array}{c}\text { Number of tearing off wheels } \\
\text { in the second, } N_{0}\end{array}$ \\
\hline 36 & 0,000103704 & 0,132577 & 0,826357414 \\
\hline 54 & 0,000187894 & 0,234206 & 1,936259785 \\
\hline 72 & 0,000285276 & 0,343818 & 2,599401495 \\
\hline 90 & 0,000378104 & 0,343818 & 2,825098256 \\
\hline
\end{tabular}

Table 6

The results of calculations the number of wheels detachments of front suspension for bus LAZ-4207 with maximum load, when it moves on cobblestone with different speeds

\begin{tabular}{|c|c|c|c|}
\hline $\begin{array}{c}\text { Speed, } \\
\mathrm{km} / \mathrm{h}\end{array}$ & $\begin{array}{c}\text { The variance of the deformation } \\
\text { of the front tire, } \sigma_{\Delta}\end{array}$ & $\begin{array}{c}\text { The variance of speed } \\
\text { deformation of front tire, } \sigma_{\dot{\Delta}}\end{array}$ & $\begin{array}{c}\text { Number of tearing off wheels in } \\
\text { the second, } N_{0}\end{array}$ \\
\hline 36 & $9,58925 \mathrm{E}-05$ & 0,123592 & 0,709096778 \\
\hline 54 & 0,000167938 & 0,227515 & 1,778768945 \\
\hline 72 & 0,000255712 & 0,317618 & 2,563299927 \\
\hline 90 & 0,000345063 & 0,361559 & 2,882826892 \\
\hline
\end{tabular}

Table 7

The results of calculations the number of wheels detachments of front suspension for bus LAZ-4207 with maximum load, when it moves on cobblestone with different speeds and maximum value of the unsprung mass

\begin{tabular}{|c|c|c|c|}
\hline $\begin{array}{c}\text { Speed, } \\
\mathrm{km} / \mathrm{h}\end{array}$ & $\begin{array}{c}\text { The variance of the deformation of } \\
\text { the front tire, } \sigma_{\Delta}\end{array}$ & $\begin{array}{c}\text { The variance of speed } \\
\text { deformation of front tire, } \sigma_{\dot{\Delta}}\end{array}$ & $\begin{array}{c}\text { Number of tearing off wheels } \\
\text { in the second, } N_{0}\end{array}$ \\
\hline 36 & 0,0001 & 0,0104 & 0,8589 \\
\hline 54 & 0,0002 & 0,2403 & 2,0131 \\
\hline 72 & 0,0003 & 0,3192 & 2,6663 \\
\hline 90 & 0,0004 & 0,3504 & 2,8541 \\
\hline
\end{tabular}

Table 8

The results of calculations the number of wheels detachments of front suspension for bus LAZ-4207 with maximum load, when it moves on cobblestone with different speeds and minimum value of the unsprung mass

\begin{tabular}{|c|c|c|c|}
\hline $\begin{array}{c}\text { Speed, } \\
\mathrm{km} / \mathrm{h}\end{array}$ & $\begin{array}{c}\text { The variance of the deformation of } \\
\text { the front tire, } \sigma_{\Delta}\end{array}$ & $\begin{array}{c}\text { The variance of speed } \\
\text { deformation of front tire, } \sigma_{\dot{\Delta}}\end{array}$ & $\begin{array}{c}\text { Number of tearing off wheels } \\
\text { in the second, } N_{0}\end{array}$ \\
\hline 36 & $9 \mathrm{E}-05$ & 0,116 & 0,571 \\
\hline 54 & 0,0001 & 0,2403 & 1,6034 \\
\hline 72 & 0,0002 & 0,31 & 2,3638 \\
\hline 90 & 0,0003 & 0,3675 & 2,8343 \\
\hline
\end{tabular}

The schedule for changing the micro-profile of cobblestone road presented in Fig. 1. In Fig. 2 the graph of wheels detachments changes per one second is presented, when bus LAZ-4207 moving on cobblestone, depending on the speed for the two weights conditions. 
Table 9

The results of calculations the number of wheels detachments of front suspension for bus LAZ-4207 unladen weight, when it moves on cobblestone with different speeds and minimum value of the unsprung mass

\begin{tabular}{|c|c|c|c|}
\hline $\begin{array}{c}\text { Speed, } \\
\mathrm{km} / \mathrm{h}\end{array}$ & $\begin{array}{c}\text { The variance of the deformation of } \\
\text { the front tire, } \sigma_{\Delta}\end{array}$ & $\begin{array}{c}\text { The variance of speed } \\
\text { deformation of front tire, } \sigma_{\dot{\Delta}}\end{array}$ & $\begin{array}{c}\text { Number of tearing off wheels } \\
\text { in the second, } N_{0}\end{array}$ \\
\hline 36 & $9 \mathrm{E}-05$ & 0,1275 & 0,6427 \\
\hline 54 & 0,0002 & 0,225 & 1,6846 \\
\hline 72 & 0,0002 & 0,3111 & 2,476 \\
\hline 90 & 0,0003 & 0,3562 & 2,8382 \\
\hline
\end{tabular}

In Fig. 3 the wheels detachments changes from the road surface per one second is presented, when the maximum loaded bus LAZ-4207 move on cobblestone road depending on the speed for the two values of unsprung masses and in Fig. 4 - the same conditions for the unloaded weight of this bus.

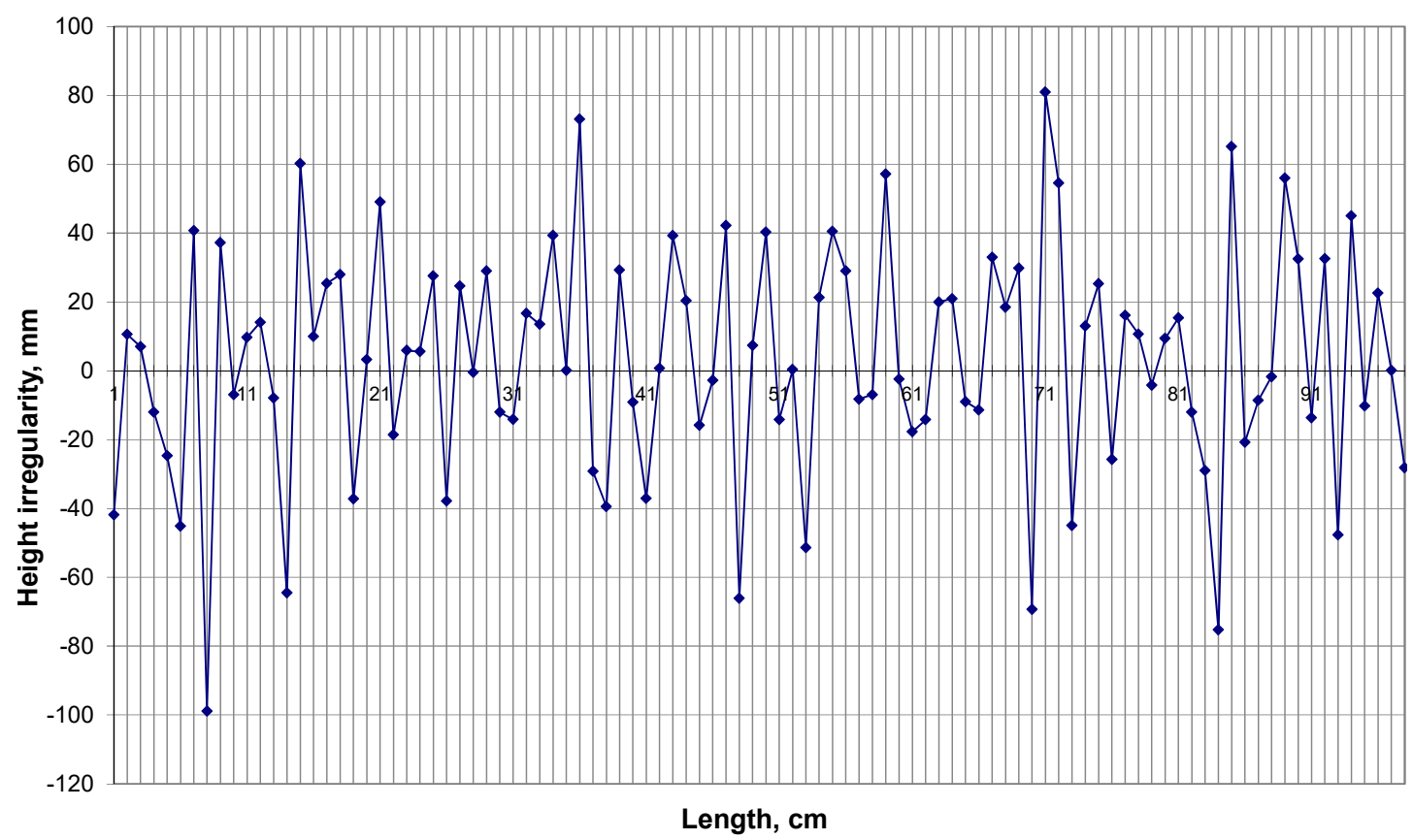

Fig. 1. The dependence of the height irregularity on the length for the plot of the cobblestone road

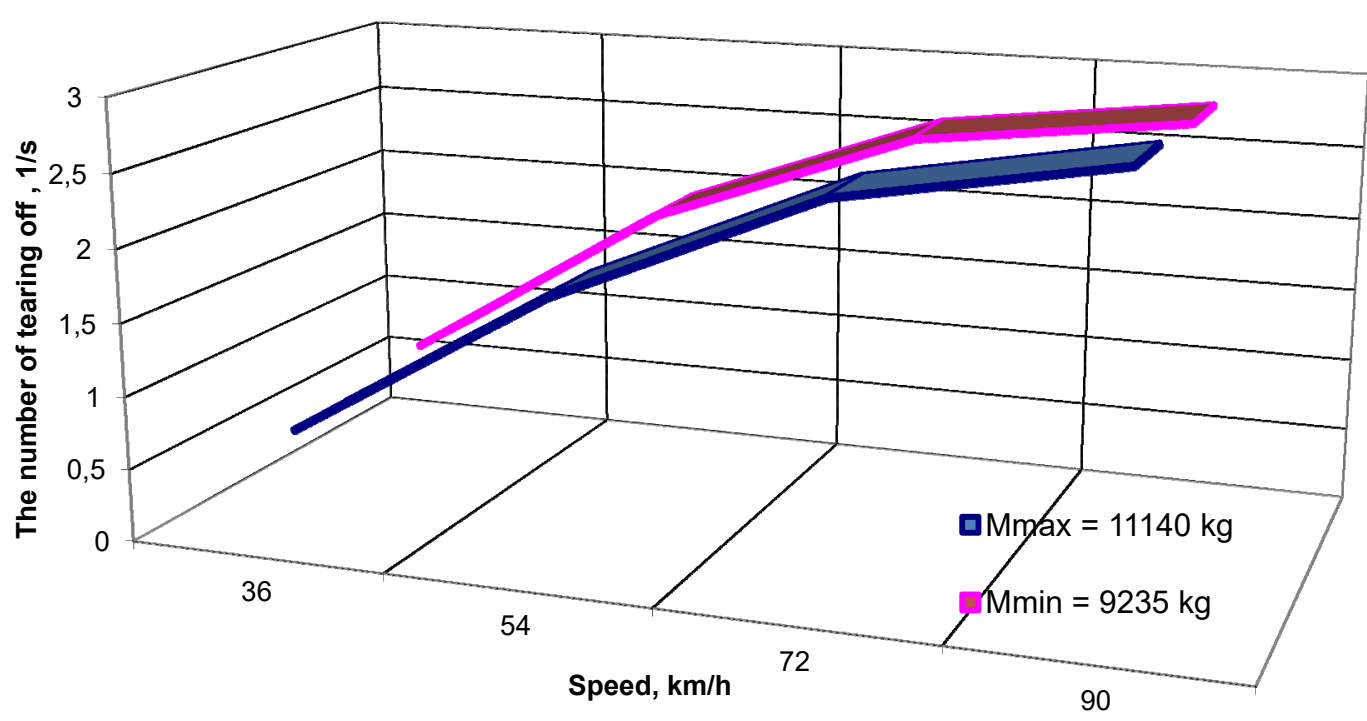

Fig. 2. The dependence of the number of tearing off the front wheels of the bus LAZ-4207 from the speed on the cobblestone road at different loading: $\mathrm{M}_{\max }=11140 \mathrm{~kg} ; \mathrm{M}_{\min }=9235 \mathrm{~kg}$ 


\section{Influence of Constructive and Oscillatory Parameters of Buses Suspension on the Road Safety}

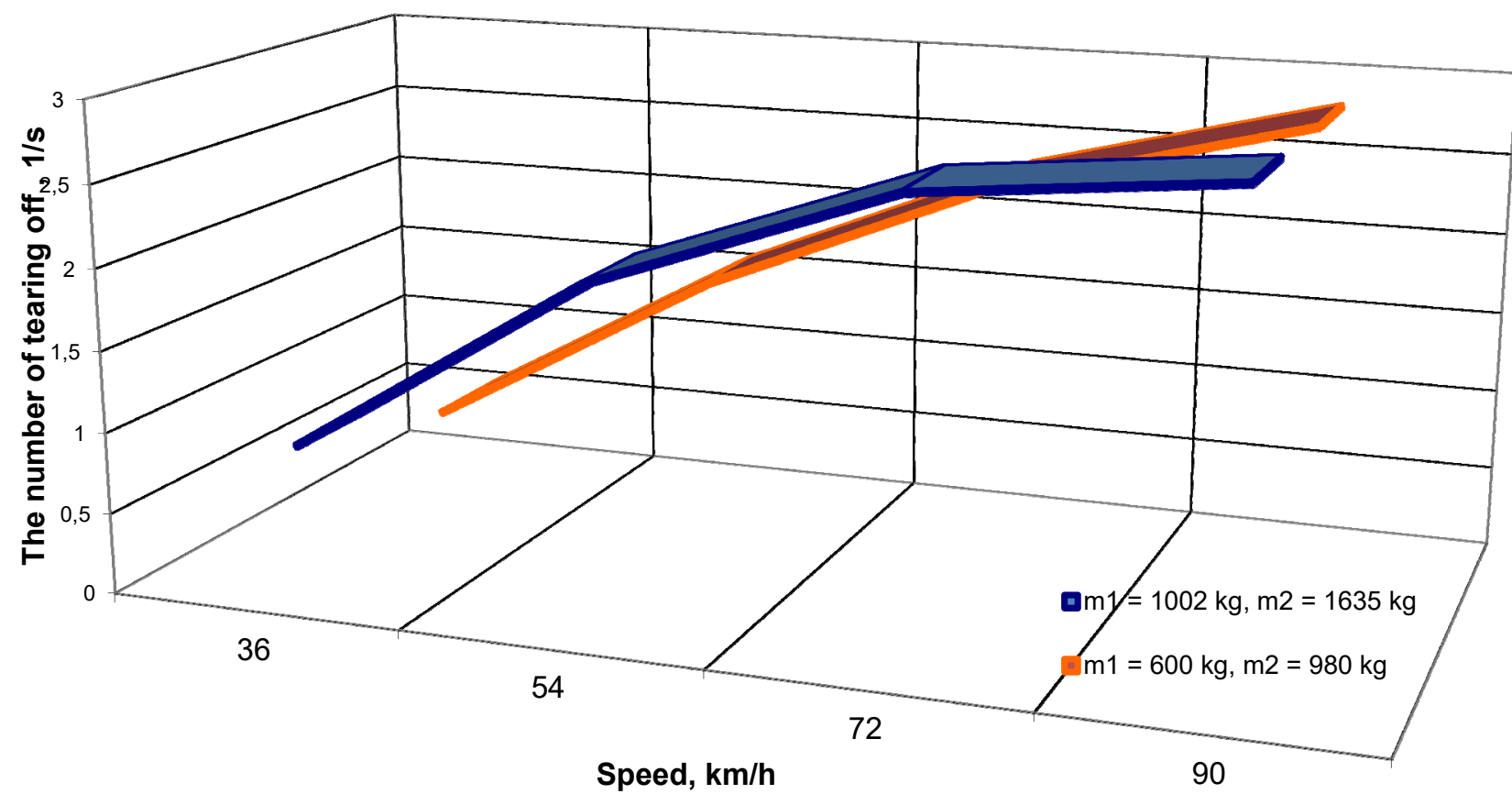

Fig. 3. Dependence of number of wheels detachments for the maximum loaded bus LAZ-4207 from the speed on the cobblestone road at different values of unsprung masses: $m_{1 \max }=1002 \mathrm{~kg} ; \mathrm{m}_{2 \max }=1635 \mathrm{~kg} ; \mathrm{m}_{1 \min }=600 \mathrm{~kg}$;

$\mathrm{m}_{2 \min }=980 \mathrm{~kg}$

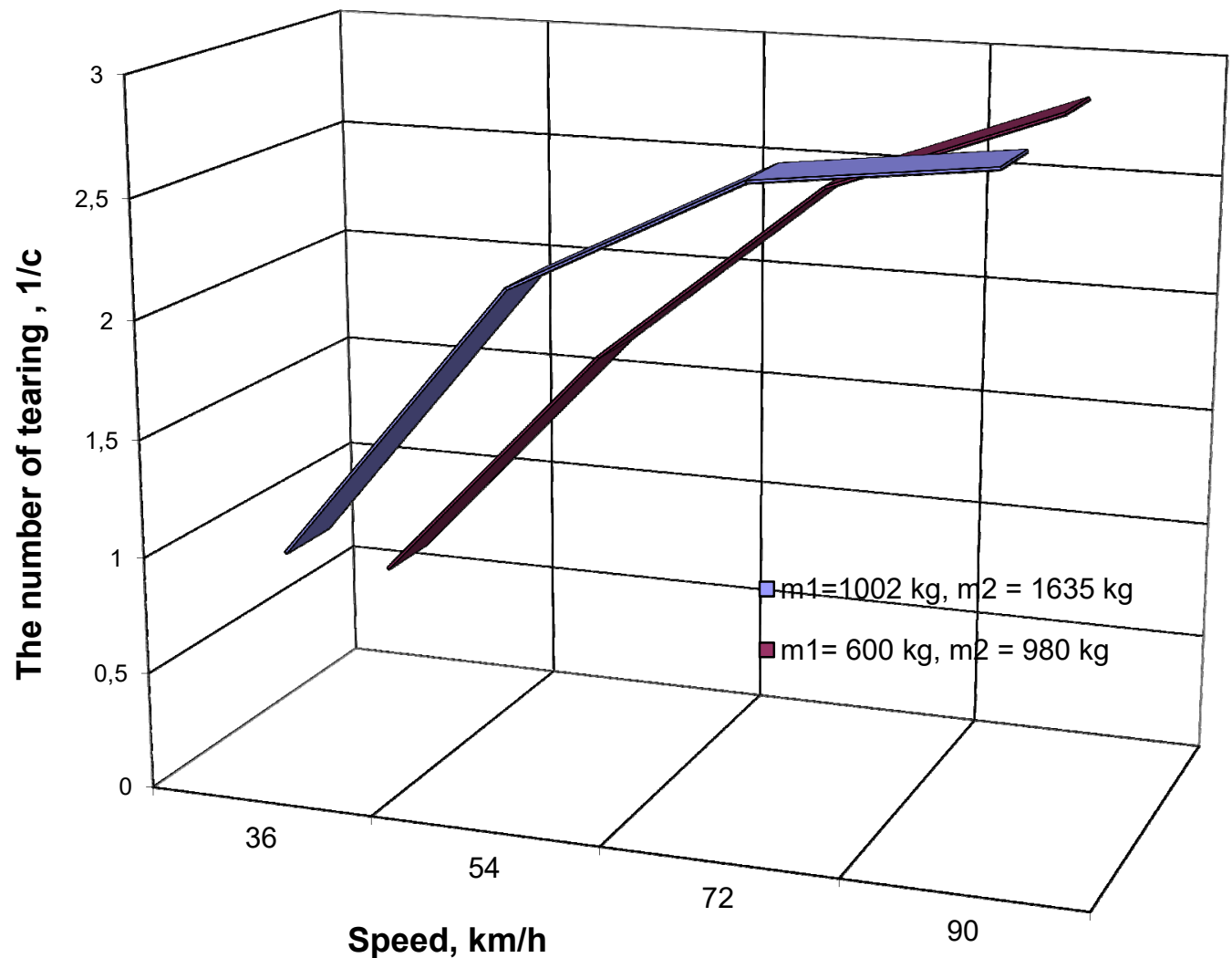

Fig. 4. Dependence of number of wheels detachments for the unloaded weight bus LAZ-4207 from the speed on the cobblestone road at different values of unsprung masses: $m_{1 \max }=1002 \mathrm{~kg} ; m_{2 \max }=1635 \mathrm{~kg} ; \mathrm{m}_{1 \min }=600 \mathrm{~kg}$; $\mathrm{m}_{2 \min }=980 \mathrm{~kg}$.

In Fig. 5 the graph of wheels detachments changes per one second is presented, when bus LAZ-4207 moving on cobblestone road, depending on the speed for the two weights conditions and at different values of tires - damping coefficient of tires and their rigidity. 

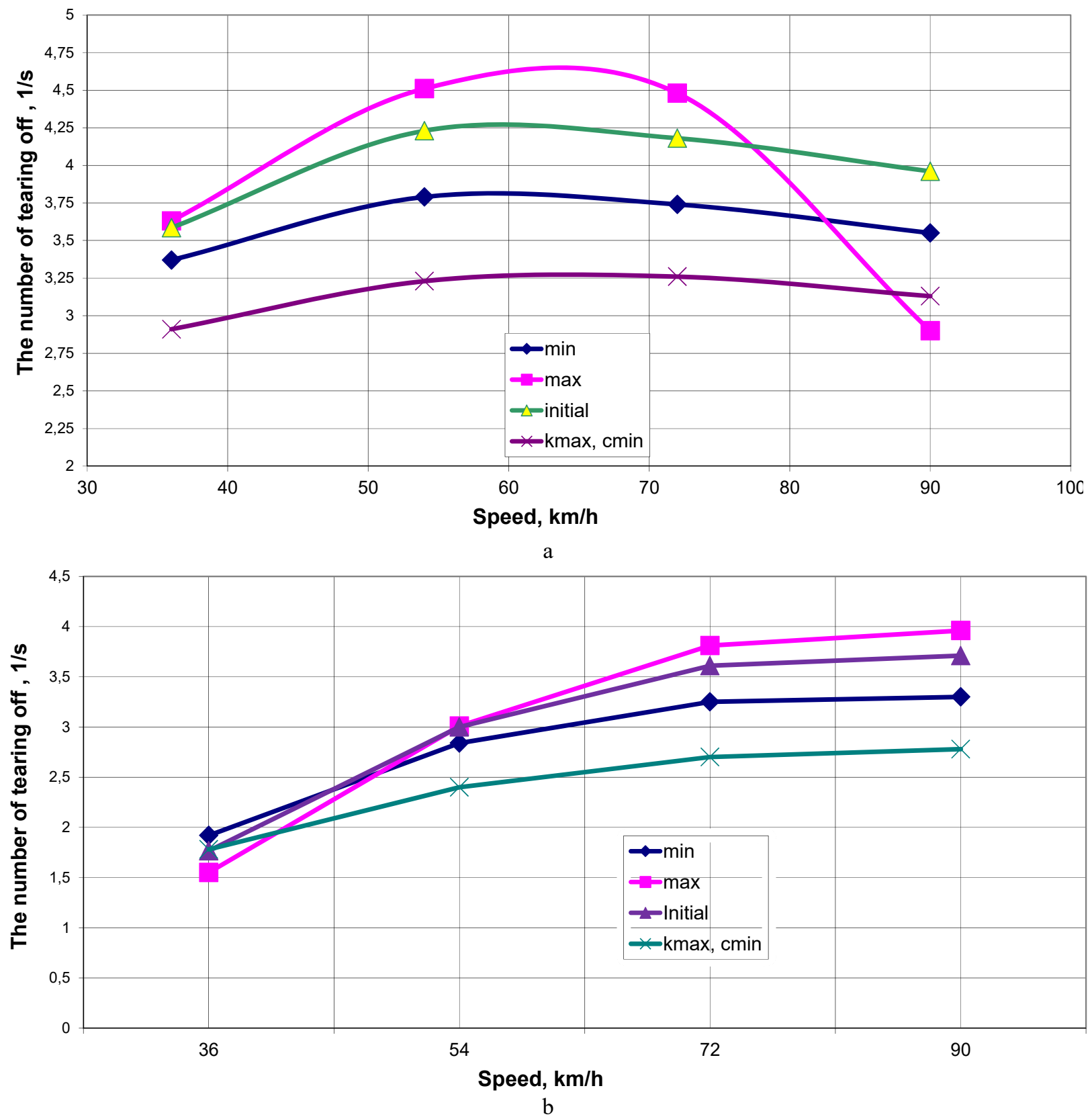

Fig. 5. Dependence of number of wheels detachments for the bus LAZ-4207 from the speed on the cobblestone road at different values of tires for two weight conditions: a - unloaded weight of a bus LAZ-4207; b - maximum loaded bus LAZ-4207

\section{Conclusions}

The methodology of determining the number of wheels detachments from the road surface when used as the main design parameters of static and dynamic deformation of the wheel and the speed of deformation changes, allows to receive data, which is agreed with other results taken by other researchers of this question [6].

The results of the research of the influence of bus load on the numbers of wheels detachments showed, that medium-operating speed range for loaded bus, when wheels are rolling without detachment is higher compare to the unloaded bus and is consistent with the results of other researchers [6]. The minimum difference among the amounts of wheels detachments on speed $90 \mathrm{~km} / \mathrm{h}$ - in favour for an unloaded bus, moreover it can be argued that the operation of the bus under such circumstances is undesirable. 


\section{Influence of Constructive and Oscillatory Parameters of Buses Suspension on the Road Safety}

The results of the study of the influence of the moments of inertia of the spring mass in the longitudinal and transversal planes (alternating static load) on the vertical movement of the wheels show, that in general increase the moment of inertia spring masses in other permanent constructive parameters, the maximum value of speed is increasing, that corresponds to the rolling wheels without detachment from the road.

Regarding the impact the value of unsprung masses, especially for bus LAZ-4207, which intended for interurban transportation with medium and high speeds, it is advisable to reduce the weight of the unsprung masses.

Worst case from the point of view of road safety, occurs during moving of the most loaded bus with a maximum value of the unsprung masses.

When you change the speed of the unloaded weight bus, it follows that the most dangerous in terms of road safety is a medium-range operations speed $(50-70 \mathrm{~km} / \mathrm{h})$ with maximum values of the coefficient of rigidity and damping of tyre, when the number of tearing off the wheels reaches a maximum $(4,51)$, but such a motion bus takes an insignificant period of time. The smallest number of front wheels detachment occurs at the maximum value of damping factor and minimum value of the rigidity of the tires $(2,91-3,13)$, that well agrees with the practical results of other researchers.

The best result for the same weight of the buses condition can be seen at minimum damping factor parameters and rigidity of the tires and the same speed of $90 \mathrm{~km} / \mathrm{h}$, when the number of front wheels detachment reaches $3.3 \mathrm{~s}^{-1}$.

The smallest number of the front wheels detachments was observed on the entire range of speeds, when installed the maximum damping coefficient and minimum rigidity of the tires to the maximum loaded bus (1.78-2.78), i.e. it indicates that traffic safety in this conditions will be optimal. If the LAZ4207 bus moves according to the following conditions (loading rate and high speed mode), it is possible to install tires with large damping properties and less rigidity.

The studies have shown, that by the selection of the optimum constructive parameters as the bus, and its suspension, should strive not only to improve the comfort of the passengers, but also take into account the possibility of deterioration of traffic safety.

Optimum smoothness of motion does not always correspond to the reduction of opportunities to wheels detachment from the road and in this matter the submitted methodology, can significantly reduce the work on designing new bus suspensions.

\section{References}

[1] R. A. Akopian, Pnevmaticheskoe podressorivanie avtotransportnykh sredstv [Pneumatic suspension of vehicles]. Lviv, Ukraine: Vyshcha shkola Publ., 1980. [in Russian].

[2] R. A. Akopian, B. U. Busel, M. M. Veremeiev, and O. V. Dubianskyi, "Shchodo vplyvu parametriv pnevmatychnoi pidvisky avtobusiv LAZ na palyvnu ekonomichnist" ["On the influence of parameters of the pneumatic suspension of LAZ buses on fuel efficiency"], in Proc. 6th Int. Conf. "Metody obliczeniowe i badawcze w rozwoju systemow pojazdow samochodowych i maszyn roboczych samojezdnych", Rzeszow, Poland, 1995, pp. 9-14. [in Ukrainian].

[3] R. A. Akopian, etc., "Vplyv deiakykh kolyvnykh parametriv avtobusa LAZ na vytratu potuzhnosti na vertykalni kolyvannia pry rusi po dorozi z riznym pokryttiam" ["Influence of some oscillating parameters of the LAZ bus on the power consumption on vertical vibrations when driving on a road with different coatings"], Proektuvannia, vyrobnytstvo ta ekspluatatsiia avtotransportnykh zasobiv i poizdiv [Design, manufacture and operation of vehicles and trains], vol. 1, pp. 8-16, 1995. [in Ukrainian].

[4] R. Akopjan, A. Dubjansky, "The method preparation for researching the influence of the road's surface on safety of bus's motion", in Proc. 3rd Int. Conf. "Prawno-ekonomiczne i techniczne aspecty bezpieczenstwa w ruchu drogowym”, Rzeszow-Krasiczyn, Poland, May 27-30, 2007, pp. 21-30.

[5] A. Dubjansky, R. Akopjan, "To the problem of an estimation of vehicle's road safety by the analysis of requirements of a continuous tire rolling", in Proc. 3rd Int. Conf. "Prawno-ekonomiczne i techniczne aspecty bezpieczenstwa w ruchu drogowym”, Rzeszow-Krasiczyn, Poland, May 27-30, 2007, pp. 11-20.

[6] A. A. Silaev, Spektralnaia teoriia podressorivaniia transportnykh mashin [Spectral theory of the 


\section{Alexander Dubjansky, Mykola Bodnar}

suspension of transport vehicles]. Moscow, Russia: Mashinostroenie Publ., 1972. [in Russian].

[7] R. Akopjan, A. Dubjansky, "Safety of rectilinear driving with the registration oscillations of controlled wheels", in Proc. 5th Int. Conf. "Avtomobilnyi transport: problemy i perspektivy" ["Automobile transport: problems and prospects”], Sevastopol, Ukraine, September 9-14, 2002, pp. 29-39.

[8] R. Akopjan, A. Dubjansky, "About one paths of lowering of rolls of a body vehicle with the pneumatic suspension in longitudinal and transversal planes", Proektuvannia, vyrobnytstvo ta ekspluatatsiia avtotransportnykh zasobiv, poizdiv ta naftohazoprovodiv [Design, manufacture and operation of motor vehicles, trains, oil and gas pipelines], vol. 9, pp. 14-18, 2002. 